\title{
Special issue in memory of Berthold Vöcking
}

\author{
Hagit Attiya ${ }^{1}$
}

Published online: 12 March 2016

(C) Springer-Verlag Berlin Heidelberg 2016

Berthold Vöcking was a member of the Distributed Computing editorial board from 2010 until he passed away in 2014 after a long illness. Berthold's interests included algorithmic game theory and mechanism design, as well as algorithms for graphs and interconnection networks. In addition to his outstanding research achievements, he contributed to the scientific community by serving on several editorial boards, chairing and organizing many conferences and workshops.
Berthold was an effective and dedicated member of the editorial board, carrying out his duties until the very last months before his death.

This issue is dedicated to his memory. It contains papers that Berthold had started to handle, as well as papers that are close to his research interests.
Hagit Attiya

hagit@cs.technion.ac.il

1 Department of Computer Science, Technion, Haifa, Israel 